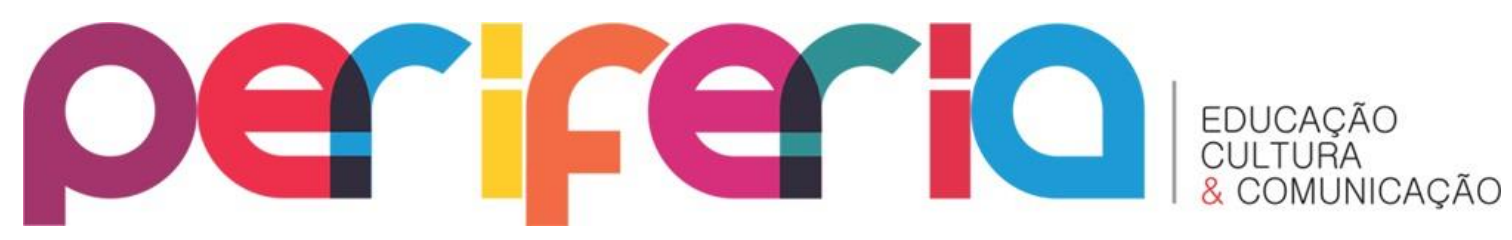

\title{
GRÊMIO ESTUDANTIL E O COTIDIANO DA ESCOLA: O JOGO POLÍTICO ESCOLAR EM UM ESTUDO DE CASO
}

\author{
Camila Moura ${ }^{1}$ \\ Pontifícia Universidade Católica do Rio de Janeiro
}

\section{RESUMO}

Este artigo apresenta reflexões oriundas de minha pesquisa de mestrado concluída em 2013 junto ao PPGE-PUC-Rio. A mesma procurou reconhecer e analisar a dimensão política de práticas sociais, por meio de estudo de caso, junto a um grêmio de estudantes. A partir da reunião e análise de dados qualitativos levantados em campo, pude observar o envolvimento do grêmio em uma espécie de jogo político escolar, caracterização justificada pela presença de dois lados (o grêmio e a escola), em disputa por espaços de atuação em um território comum (o colégio). A política, neste sentido, foi concebida como prática cotidiana e experiência formativa, espaço de vivência e da relação com o outro, ancorada nas perspectivas da estratégia de convivência (PARO, 2002) e na relação amigo-inimigo (BOBBIO, 1986; SCHMITT, 1992). No caso estudado, concluiu-se que, a partir de seu envolvimento no jogo político escolar, os estudantes buscavam transformar seu cotidiano educacional, utilizando negociação e barganha na disputa por espaços de atuação e maior liberdade de ação em sua escola, prática reconhecida como possuidora de forte dimensão política, conferindo às instituições de ensino potencial considerável na construção de uma experiência política formativa nos estudantes.

Palavras-Chave: grêmios escolares, experiência política formativa, cotidiano escolar.

\section{GRÊMIO ESTUDANTIL AND THE SCHOOL ROUTINE: SCHOOL POLITICAL GAME IN A CASE STUDY \\ ABSTRACT}

The paper presents reflections belonging to my master's research, completed in 2013, at PPGE-PUC-Rio, which sought to recognize and analyze the political dimension of social practices through a case study of a grêmio de estudantes. From the collection and analysis of qualitative data collected in field, I observed the involvement of the grêmio in a kind of political game school. This characterization is justified by the presence of two sides (the guild and school) in contention for performance spaces in a common territory (the college). Politics, in this sense, is conceived as a daily practice and formative experience, place where relationship with the other exist, this conception is anchored by the perspective of coexistence strategies (PARO, 2002) and the relationship friend-enemy (BOBBIO, 1986; SCHMITT, 1992). In the case studied, it was concluded by the involvement at the political game school the students "agremiados" sought to transform their educational routine,

\footnotetext{
${ }^{1}$ Graduada em História pela UFF (2004), mestre em Educação pela Pontifícia Universidade Católica do Rio de Janeiro (2013) e doutoranda em educação pela mesma universidade (2013-2017). Membro do Grupo de Pesquisa em Educação e Mídia (GRUPEM), da PUC-Rio. E-mail: pintocamilam@yahoo.com.br
} 


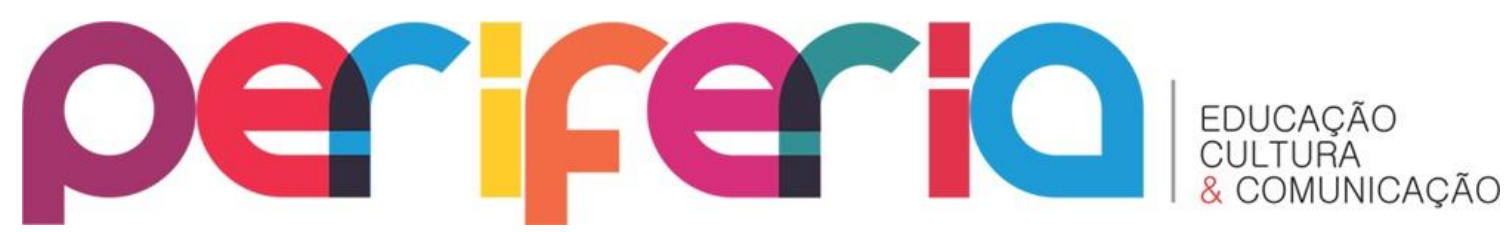

using negotiation and bargaining to get more autonomy act in their school. Those characteristics were recognized as holder of strong political dimension practice, giving to the educational institutions strong potentials to build a formative political experience in students.

Keywords: Grêmios escolares; formative political experience; daily school.

\section{JUVENTUDE E POLÍTICA: UMA INTERFACE EM CONSTRUÇÃO}

Não seria leviano afirmar que na área da Educação são ainda escassos os trabalhos acadêmicos que se debruçam sobre o tema da política como interface na experiência formativa dos jovens. Ainda mais raras são as pesquisas que possuem como objeto central os grêmios de estudantes. Unir os dois objetos é o objetivo deste artigo, uma pequena tentativa de atenuar essas lacunas.

Partindo do ponto de vista de Sposito (2000), as investigações sobre a juventude no Brasil ganharam espaço nos meios acadêmicos a partir da década de 1960. A maioria dessas pesquisas tinha como parâmetro o modelo de participação juvenil construído por Marialice Foracchi (1965) no livro $O$ estudante $e$ a transformação da sociedade brasileira.

Inspirada em seus trabalhos [nos de Foracchi], a produção acadêmica, tanto na área da Educação como de Ciências Sociais, durante as décadas seguintes, tratou com menor frequência do tema [juventude], (...) mas, com pouco vigor teórico e inovação ao tentar compreender as alterações dessas práticas nos períodos mais recentes, marcados por um gradativo enfraquecimento das formas tradicionais de mobilização e seu escasso poder de aglutinação de demandas e interesses do conjunto dos estudantes (SPOSITO, 2000, p.79).

Historicamente situadas, as pesquisas sobre a participação política da juventude no movimento estudantil dos anos 1960 são precursoras nos estudos sobre juventude no Brasil e durante muito tempo serviram como referência para a compreensão da relação dos jovens com a política. Pertencer ou não ao movimento, engajar-se ou não nas lutas contra a ditadura eram referências chave para "avaliar" o grau das ações e da participação política dos jovens. Contudo, essa tendência se modificou ao longo dos anos. A partir do levantamento coordenado por Marília Sposito $(2002,2009)$ das teses e dissertações das pesquisas sobre a juventude no 


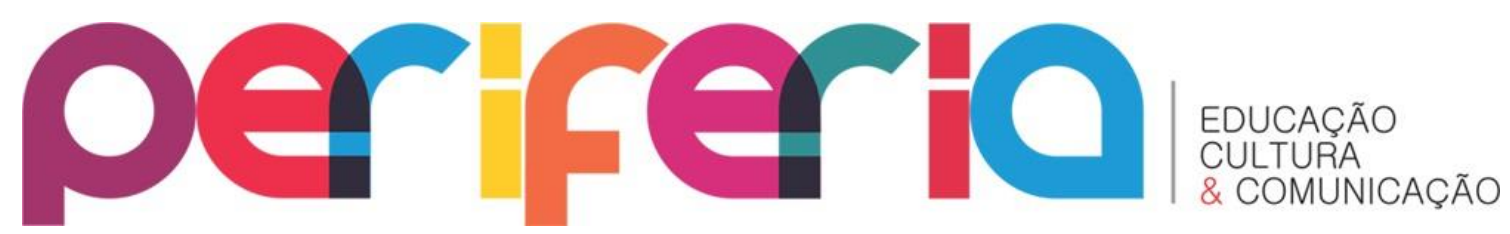

Brasil, defendidas entre os anos de $1980-1998^{2}$ e $1999-2006^{3}$, é possível constatar essa mudança de paradigma.

De acordo com Paulo Carrano (2002), que atuou como pesquisador em ambos os levantamentos, entre 1980 e 1984 não foram encontrados registros de pesquisa sobre o tema jovens e participação política, o que, em sua visão, evidencia um silêncio sobre a questão nos primeiros anos de redemocratização política no país. Contudo, a partir de 1985 foram defendidos alguns trabalhos com enfoque histórico, procurando recuperar as mobilizações estudantis durante a ditadura militar. Nessas pesquisas, afirma o autor, a dicotomia engajamento/alienação aparece na quase totalidade das investigações e é utilizada como parâmetro na compreensão da participação política da juventude, pois estavam preocupadas em conferir a eficácia do movimento estudantil e da ação política dos jovens na transformação da sociedade. Todavia, foi somente a partir de meados dos anos 1990 que análises que procuram abrir esse debate considerando a existência de formas de ação e expressão política da juventude, que vão além tanto da perspectiva do engajamento no movimento estudantil quanto do binômio engajamento/alienação, começam a ser defendidas.

Esses trabalhos procuraram ampliar a busca por novos espaços e sentidos da participação política da juventude, pois acreditavam que enfocar apenas o movimento estudantil e sua adesão ou não pelos jovens, encaixando-os em dicotomias de ação, seria insuficiente para tratar das complexas e diversas questões

\footnotetext{
2 O primeiro levantamento, Juventude e escolarização (Sposito, 2002) levou em consideração as investigações sobre juventude na área da Educação. De acordo com o mapeamento, os trabalhos que tinham como objeto de pesquisa a juventude representavam $4,4 \%$ do total de pesquisas na área. Dentre estes trabalhos o tema "Participação política" corresponde a 5,94\%. As análises sobre esse tema deram origem ao artigo Participação política dos jovens, de Paulo Carrano (2002).

${ }^{3}$ O segundo levantamento analisou as produções acadêmicas sobre juventude entre os anos de 1999 e 2006; além de abranger a área da Educação, incorporou as Ciências Sociais (Antropologia, Ciência Política e Sociologia) e o Serviço Social. Na área da Educação, as pesquisas tiveram tímido aumento, passando de $4,4 \%$ no primeiro para $6 \%$ no segundo. Dentre esses trabalhos, o tema "Cultura e Participação Política" (que remete aos estudos interessados na relação entre juventude e política) representa $4,4 \%$ do total de trabalhos analisados; esse percentual é de 3,5\%, quando observadas as produções na área da Educação. As análises desse tema deram origem ao artigo Estudos sobre jovens na interface com a política, de Sposito et al. (2009).
} 


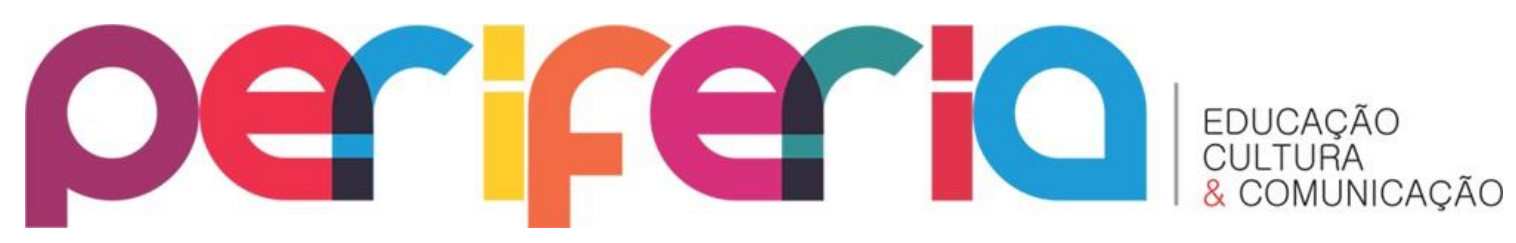

que envolvem as reflexões sobre juventude e política. "É interessante notar que o inconformismo dos jovens estudantes não orientado para as transformações globais da sociedade foi, via de regra, considerado irrelevante politicamente" (CARRANO, 2002, p.198).

Os trabalhos mais recentes, em especial aqueles situados a partir de meados dos anos 1990, apontam como direção interpretativa a crise de representatividade e seu efeito na descrença dos jovens na democracia representativa e seu impacto na desmobilização política da juventude. O trabalho de Mische (1997), por exemplo, chama a atenção para a descontinuidade do movimento Cara Pintada após a deposição do presidente Fernando Collor, em 1992. Já o de Mesquita (2003) chama a atenção para a falta de fôlego do movimento estudantil e aponta para seu gradual enfraquecimento como canal de participação política da juventude, devido à falta de capacidade de aglutinação manifesta em sua intervenção fragmentada, sem falar em sua pouca expressividade entre os estudantes...

Os levantamentos coordenados por Sposito $(2002,2009)$ levam à conclusão de que, mesmo possuindo avanço, ainda são escassas as pesquisas sobre juventude e política que reconheçam o valor de iniciativas não necessariamente vinculadas às instituições políticas ou ao movimento estudantil como espaços realmente válidos na interface entre juventude e política. Também são desconsideradas como políticas as ações que não necessariamente reivindiquem mudanças estruturais na sociedade, marcando ainda nos dias de hoje, como referência válida de participação política, a atitude revolucionária assumida pela "geração de 68". Normalmente são excluídas como manifestação do político e, consequentemente, do conceito de política certos valores éticos e morais por trás de ações dos jovens que resgatem o bem comum e a civilidade, vistos especialmente em ações voluntárias, ecológicas, grupos de debates ou mesmo atividades desenvolvidas em outros locais, como suas próprias escolas. Igualmente ausentes estão as expressões do político no trato e nas interações cotidianas, nas relações e no papel formativo da política na vida dos jovens.

Procurando suprir algumas dessas lacunas, desenvolvi uma pesquisa de 


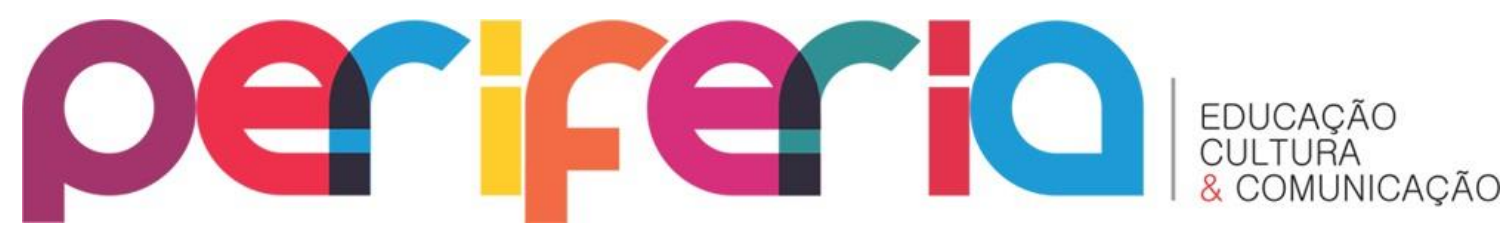

mestrado junto ao Programa de Pós-Graduação em Educação Brasileira da PUC-Rio buscando reconhecer e analisar, a partir de um estudo de caso, a dimensão política de algumas atividades e práticas sociais realizadas por um grêmio de estudantes atuante em uma escola confessional católica da cidade do Rio de Janeiro no ano de $2012^{4}$. A pesquisa buscou compreender a manifestação do político no cotidiano escolar como experiência formativa, no sentido de possibilitar a construção e troca de saberes inerentes à política, tais como a capacidade de negociação e de ação estratégica ou até mesmo a capacidade de agir conforme a lógica dos fins e dos meios...

Para além de uma concepção tradicional de politização da juventude manifesta, por exemplo, em seu pertencimento ao movimento estudantil ou até mesmo no que consiste sua atuação "cidadã-eleitoral", o estudo de caso procurou compreender a dimensão política das práticas sociais presentes no cotidiano dos jovens, no seu dia a dia como estudantes. Nesse sentido, estou de acordo com Schmitt (1992) que, ao conceituar o político, coloca-o como inerente aos comportamentos humanos, inserido no leque de possibilidades de ação dos sujeitos, tanto relacionado à motivação para a ação quanto à ação em si mesma, podendo manifestar-se, dessa forma, nos mais diversificados tipos de relações sociais. "A equivalência estatal = político mostra-se incorreta e enganosa, na mesma medida em que o Estado e sociedade se interpenetram, todos os assuntos até então políticos, tornam-se sociais e vice-versa" (SCHMITT, 1992, p. 47).

Pressupondo uma forma ampliada de compreender a política, questiono-me sobre sua manifestação no interior das instituições de ensino, visto que a escola, além de ser organizada com o fim de educar, também é um espaço de socialização, de trocas culturais e formação ética e moral; logo, propício à manifestação do político.

\footnotetext{
${ }^{4}$ A escolha da escola pesquisada seguiu algumas orientações metodológicas de Robert Yin (2010). De acordo com o autor, a unidade a ser investigada deve ser primeiramente confrontada com outras unidades possíveis de análise. Na pesquisa de mestrado foram realizados três "miniestudos" em três diferentes perfis escolares, a partir de referências levantadas pelo Soced - Grupo de Pesquisa em Sociologia da Educação da PUC-Rio. A partir da análise desses três "miniestudos", optei por desenvolver a pesquisa na escola confessional.
} 


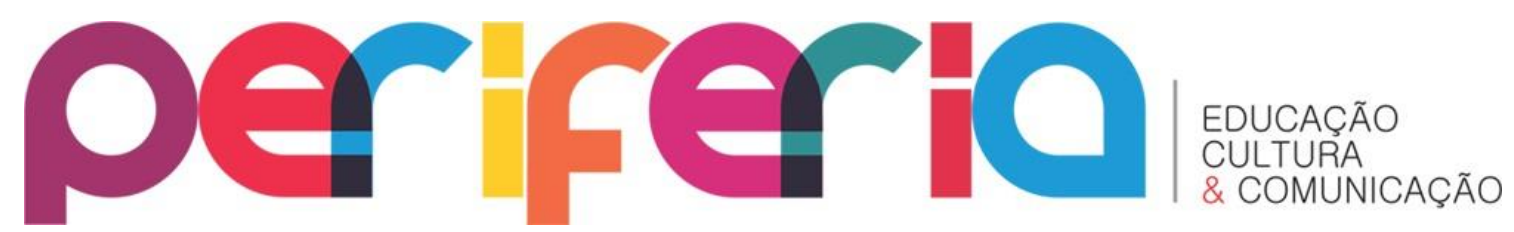

Assim, mais do que uma instituição social com a função de formar e educar os cidadãos, a escola foi considerada espaço sociocultural (DAYRELL, 1999), ou seja, lugar do encontro, das trocas de experiências, do intercâmbio cultural e das interações sociais, portanto propício à experiência política formativa. Levando em consideração essa concepção, a investigação teve como enfoque as trocas e interações próprias do espaço escolar, valorizando sua dimensão política. Assim, as diversas situações de negociação, conflito, alianças e rupturas que envolviam o grêmio e membros da instituição de ensino foram compreendidas como manifestação do político no cotidiano escolar.

Foi observado no estudo de caso que a quase totalidade das ações do grêmio eram centralizadas no colégio. Palestras, assembleias, concursos literários, competições de música, apresentações de peças teatrais e debates com candidatos a cargos públicos são apenas alguns exemplos de eventos organizados por seus integrantes. Todas elas tiveram como palco sua escola e carregavam em si forte dimensão política. "A essência da política consiste em [...] luta, recrutamento de aliados e de seguidores voluntários" (SCHMITT, 1992, p. 44). Essas ações foram interpretadas como políticas, pois frutos de processos de interação e mobilização dos estudantes sob dois aspectos: seja em torno de atividades comuns, organização e desenvolvimento de atividades, revelando a manifestação do político enquanto capacidade de formar alianças, no sentido de constituir um grupo mobilizado; seja no processo de negociação e conflito com os demais membros da comunidade escolar ${ }^{5}$ na produção dessas atividades. Ambos os aspectos envolvem a relação amigoinimigo (BOBBIO, 1986, SCHMITT, 1992) e estratégias de convivência (PARO, 2002,

\footnotetext{
${ }^{5}$ De acordo com o site da instituição de ensino o grêmio, assim como a Associação de Pais e Mestres, as Coordenações Pedagógicas do Ensino Fundamental e Médio e a Direção entre outros setores da administração escolar, compõem a comunidade escolar, em que cada um possui papel decisivo na formação dos alunos. O espaço é organizado administrativa e institucionalmente com a finalidade de educar para a transformação social. Esse objetivo é expresso em diferentes documentos, como regimento escolar, projeto político-pedagógico da escola, folders de propaganda, em folhetos explicativos etc. No mesmo site há referência àquilo que a instituição de ensino denomina apoio pedagógico, formado pelos grêmios, associação de pais e mestres, associação de ex-alunos, bibliotecas e cursos extraclasse.
} 


\section{periferio}

2010) como categorias-chave.

A instituição de ensino, desse modo, foi compreendida sob a metáfora de um tabuleiro, um território em disputa, em que os estudantes competiam por maior liberdade de ação e organização. Compreendi que o que ditava a tônica da dimensão política das ações do grêmio pesquisado, que recebeu o nome fictício de Spoleta 2.0, era a procura por brechas de atuação no sentido de transformar sua realidade, a situação de dominação em que se encontrava frente à organização hierárquicaadministrativa de sua escola ${ }^{6}$. Na visão dos estudantes, os diferentes setores de seu colégio influenciavam de forma negativa as ações do grêmio, "burocratizando-as". A organização estrutural do colégio representava para os integrantes do Spoleta 2.0 situações latentes de conflito (político), visto que sua posição nesta hierarquia encontrava-se subjugada, em especial à Coordenação Pastoral.

Devido a essa configuração particular, as observações de campo e análises do material empírico focaram a relação do grêmio com essa coordenação, buscando compreender como eram negociados e construídos os espaços de atuação do grêmio, reconhecendo sua dimensão política. Por buscarem transformações em sua experiência escolar, a partir da luta por maiores espaços de atuação e autonomia na organização de suas atividades, os integrantes do grêmio foram considerados sujeitos políticos atuantes em sua realidade. Nesse sentido, o jogo político escolar ganha vida no conflito cotidiano e na construção de caminhos participativos no interior da escola, sendo um aspecto extremamente relevante na experiência política formativa dos jovens.

\footnotetext{
${ }^{6}$ A burocracia e a estrutura organizacional do colégio revelaram-se aspectos centrais no caso estudado. Havia um "peso" burocrático e institucional, representado pela Coordenação Pastoral (C. P.) da escola, que influenciava a organização das atividades do grêmio. O setor ocupava a posição, na estrutura organizacional do colégio, de mediador e interlocutor com o grêmio e os demais segmentos da escola. Essa situação configurava, em suma, que todas as ações do Spoleta 2.0, deveriam ser negociadas e organizadas junto à C. P.
} 


\title{
periferio
}

\section{O JOGO POLÍTICO ESCOLAR: TRANSFORMAÇõES DA REALIDADE COTIDIANA COMO EXPERIÊNCIA POLÍTICA FORMATIVA}

O estudo de caso partiu do pressuposto de que reconhecer e analisar a dimensão política de práticas sociais de um grêmio de estudantes significa, sobretudo, observar como se constituem as relações de convivência cotidiana entre seus membros e o restante da comunidade escolar. Outro princípio do estudo foi buscar compreender o sentido político dessas relações, compreendendo a escola como espaço sociocultural, ou seja, como também um lugar de troca e de experiências formativas. Essa concepção resgata o papel dos sujeitos na trama que a constrói como instituição social (DAYRELL, 1999) e não meramente como local destinado à aprendizagem, sendo possível, no entanto, atribuir ao espaço escolar uma dinâmica social, cultural e política própria.

\begin{abstract}
Apreender a escola como construção social implica, assim, compreendê-la no seu fazer cotidiano, em que os sujeitos não são apenas agentes passivos diante da estrutura. Ao contrário, trata-se de uma relação em contínua construção, de conflitos e negociações em função de circunstâncias determinadas. A escola, como espaço sociocultural, é entendida, portanto, como um espaço social próprio, ordenado em dupla dimensão. Institucionalmente, por um conjunto de normas e regras, que buscam unificar e delimitar a ação de seus sujeitos. Cotidianamente, por uma complexa trama de relações sociais entre os sujeitos envolvidos, que incluem alianças e conflitos, imposição de normas e estratégias individuais, ou coletivas, de transgressão e de acordos. Um processo de apropriação constante de espaços, das normas, das práticas e dos saberes que dão forma à vida escolar. Fruto da ação recíproca entre o sujeito e a instituição, esse processo, como tal, é heterogêneo. Nessa perspectiva, a realidade escolar aparece mediada, no cotidiano, pela apropriação, elaboração, reelaboração ou repulsa, expressas pelos sujeitos sociais (DAYRELL, 1999, p. 2).
\end{abstract}

Era necessário observar, desse modo, tanto a organização escolar, no sentido de sua estrutura organizacional-administrativa (burocratizada e hierarquicamente normatizada), quanto a trama de relações sociais construídas em torno dessa disposição. Vale ressaltar que foi levado em consideração, em ambas as situações, em primeiro plano a posição e o lugar ocupado pelo grêmio nesse arranjo. 


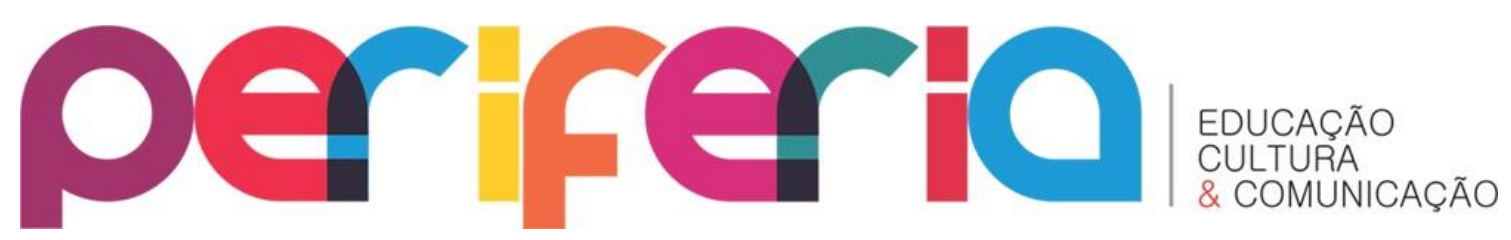

Vitor Paro (2000, 2002, 2010) argumenta que a escola, na condição de instituição social formadora, possui a finalidade central de promover o ensino. Para cumprir tal desígnio, organiza-se de modo a alcançar esse objetivo, o que pressupõe carregar em sua organização preceitos administrativos. Alerta, contudo, que no caso da administração escolar deve ser enfatizada não sua função administrativa per se, mas sua intrínseca dimensão mediadora. De acordo com esse autor, portanto, o arranjo organizacional de uma instituição de ensino deve ser compreendido para além de sua função meramente administrativa e normativa, tendo em vista que antes de se prestar a unir e otimizar o funcionamento da mesma, sua organização tem por finalidade maior a mediação da aprendizagem dos estudantes.

O que podemos extrair da fala desses autores, em suma, é que uma escola, teoricamente, deveria ser organizada visando à aprendizagem mediada, conciliando seu papel como instituição social provedora de ensino-aprendizagem e mediadora cultural responsável pela criação de condições para vivências e experiências formativas. Quando olhamos para o "chão da escola", contudo, é inevitável pensar na existência de uma radical tensão norma X prática / arranjo institucional X prática social como uma visível recorrência nas diversas e singulares realidades institucionais.

No caso estudado, essa tensão aparece constantemente, assumindo uma das características centrais e uma das mais visíveis do jogo político escolar. De acordo com a organização institucional, a Coordenação Pastoral (C. P.) tem a função de mediar a relação do grêmio com os demais setores da escola. Isso significa, na prática, que qualquer ação a ser promovida pelo Spoleta 2.0 deve ter o "aval" da C. P. É, portanto, dentro de uma relação de dominação hierárquica (normativamente justificada, dado o arranjo organizacional do colégio) que o jogo político dava suas cartas. Observe o trecho a seguir, em que um dos representantes da coordenação explica seu papel junto ao grêmio.

- Então, o nosso papel enquanto Coordenação Pastoral é tentar manter a unidade da missão da instituição. (...) O nosso papel é exatamente dar essa unidade à perspectiva da missão da instituição. 


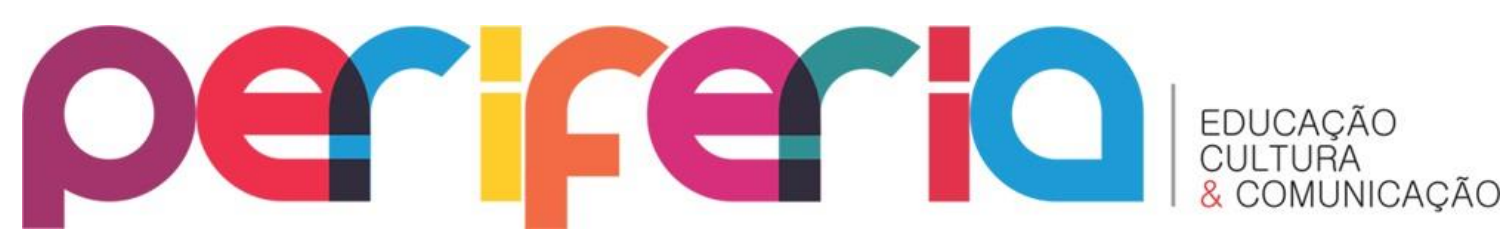

- E vocês são uma instituição à parte da escola? [fala da pesquisadora]

- Não, apesar de muitos pais acharem. Nós somos um grupo de três pessoas. Não somos uma coordenação pedagógica, mas também não deixamos de ser. Mas é uma coordenação de integração, de parceria, de construir coisas. Quem puxa um pouco esse carro, essa proposta, é essa equipe. Tem a dimensão pastoral, religiosa, tem a dimensão comunitária, tem a dimensão social.

- Então, todos os segmentos da escola passam por aqui de alguma forma? [fala da pesquisadora]

- Todos os segmentos da escola dialogam conosco [Trecho retirado da entrevista junto a um membro da Coordenação Pastoral].

Contudo, a visão integradora que o representante da coordenação apontou como sendo a função da C. P. afastava-se da concepção e opinião dos estudantes envolvidos com o grêmio sobre ela. Um deles relatou que a atuação da coordenação assemelhava-se à de um órgão regulador e fiscalizador das atividades do grêmio. Chamou atenção para o aspecto excessivamente burocrático assumido pela mesma, situação que acabava por interferir na execução de certas atividades desenvolvidas.

- Eles são funcionários da escola. É um órgão que, na teoria, é importante, no sentido de que todos os outros setores da escola devem convergir pra lá, pra ela fazer o alinhamento dos dados de tudo que acontece na escola. Teoricamente, eles serviriam para convergir esses dados [atividades desenvolvidas por diferentes setores da escola, desde o grêmio, à biblioteca, passando por festas etc.] e tentar estabelecer um equilíbrio, para não ficar cinco coisas marcadas no mesmo dia, tentando criar uma harmonia. Mas o que acontece é que a C. P. é um órgão extremamente burocrático. Eles fazem algumas coisas sem uma reflexão do que se está fazendo. É uma coisa mecânica, feita no automático. Tipo: já faço isso há tantos anos, vou continuar fazendo. E fora que é um sistema altamente burocratizado, então cometem-se falhas, só que quando essa falha diz respeito à gente, a culpa é nossa. Então o que eles acabaram se tornando? Um órgão fiscalizador e cerceador das atividades do grêmio. Então, tem várias coisas em que a gente prefere passar diretamente por cima deles.

O papel de mediação exercido pela C. P. continha diferentes significados, havia uma tensão amigo-inimigo o tempo todo no ar. Essas falas, contudo, devem ser relativizadas, pois na prática, observando a interação dos jovens com a coordenação, saltava aos olhos o clima ora de aliança, ora de rivalidade, ora de parceria, ora de 


\section{Oerforta}

antagonismo. Essa tensão, negociada situação a situação, atividade a atividade, evento a evento, norteava a relação entre o grêmio e a coordenação.

As duas últimas frases do último trecho são muito interessantes e elucidam a existência do jogo político mencionado. A Coordenação Pastoral é colocada como um órgão regulador e cerceador das atividades do grêmio, marcando uma latente situação de dominação, do ponto de vista dos jovens. Contudo, a afirmação: "tem várias coisas que a gente prefere passar diretamente por cima deles" sugere que, apesar de estarem inseridos em uma situação de controle, era possível desenvolver estratégias e "passar por cima" da coordenação. Era possível atuar nas brechas do controle, e essa atuação na fenda da dominação era o que possibilitava aos jovens vivenciar uma experiência política formativa.

Apesar de dispostos em disputa, essa batalha não se desenrolava em um ambiente hostil ou conflituoso. $\mathrm{O}$ jogo político escolar caracterizou-se indiscutivelmente pela via da negociação, pela atuação nas brechas, na estratégia de convivência e na construção de relações do tipo amigo-inimigo, ou seja, pelos meandros da política.

- A gente partilha do princípio de que às vezes o não não é nada educado, mas a troca é fundamental para que haja o processo educativo (...). Então, não existe entre aspas a palavra não, mas existem as palavras vamos tentar, vamos construir [fala de um dos representantes da Coordenação Pastoral].

Do lado da Coordenação Pastoral, o uso do não, por exemplo, é administrado de forma bastante "democrática", pois pode repercutir de forma extremamente negativa, reforçando estereótipos de dominação e autoritarismo, atitude reprovada como parte do processo pedagógico e da missão da escola. A posição tomada como estratégia de convivência da C. P., nesse sentido, é o diálogo, a negociação, a construção democrática das ações. Essa posição reflete uma visão institucional propensa ao debate. A construção de relações do tipo amigo era privilegiada, neste caso. 


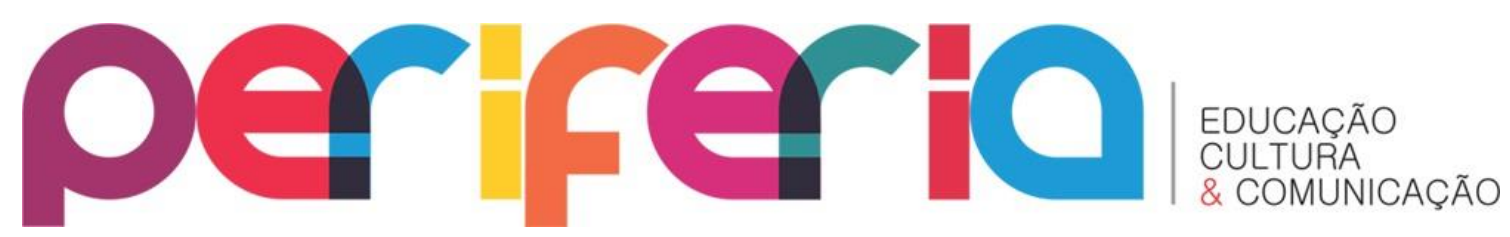

No caso dos estudantes, o princípio a ser seguido parecia o mesmo. $\mathrm{Na}$ opinião deles, não adiantava confrontar, "bater de frente" com a Coordenação Pastoral. Os alunos entendiam que a melhor maneira de transformar sua situação seria conquistando, aos poucos, espaços de atuação, mostrando à coordenação o quanto eram capazes, maduros e merecedores de certas concessões ${ }^{7}$. Mostrar que são capazes e maduros seria, a meu ver, uma maneira de assumir uma posição estratégica de convivência.

Dentro das atividades organizadas pelos estudantes, uma chamara muito minha atenção, devido ao alto grau de autonomia e independência dos estudantes em sua organização. Compreendi sua idealização, produção e condução como espaços altamente incentivadores à experiência política formativa, pois representava uma postura diferenciada dos estudantes em relação à C. P. Tratava-se de um evento denominado SISV - Simulações ONU-Junior, em que sessões da ONU eram simuladas, organizadas com debates sobre alguns temas próprios da política internacional. $\mathrm{O}$ evento durou uma semana e mobilizou mais de cem estudantes, entre participantes e organizadores. Falando sobre o sucesso dele, uma jovem do grêmio afirmou:

- Porque os professores, na hora que eles viram, a coordenação, na hora que eles viram que a gente já tava com tudo pronto, que tinha até convidado, que já estávamos com os guias certos, que já tava tudo pronto. Aí eles começaram a levar a sério e, aí eu acho que o grêmio ganhou um espaço. Agora a gente tem isso. A gente fez o SISV sozinho. Então, por que a gente não pode ter a chave da nossa sala? A gente fez não sei o que sozinho, por que que a gente não pode ter acesso à internet? Por que vocês acham que a gente, sei lá, vai ficar vendo pornografia na escola...

A luta por espaços de atuação foi detectada como a grande "bandeira política" dos estudantes, a principal causa que os movia. Contudo, é preciso marcar

\footnotetext{
${ }^{7}$ Estas concessões referiam-se, diretamente, à posse da chave da sala do grêmio, ao acesso à internet, à mudança para uma sala maior, a maior liberdade de editar o jornal, a agir mais livremente dentro da escola com relação à organização de eventos etc. Essas reivindicações eram somadas a outras, como maior participação nas decisões do Conselho Pedagógico, reunião realizada semanalmente e que abriga todos os setores da escola, maior liberdade e autonomia na gestão e uso da verba destinada ao grêmio etc. A luta por espaços, dessa forma, configurava-se tanto do ponto de vista físico quanto simbólico, remetido às próprias ações dos estudantes.
} 


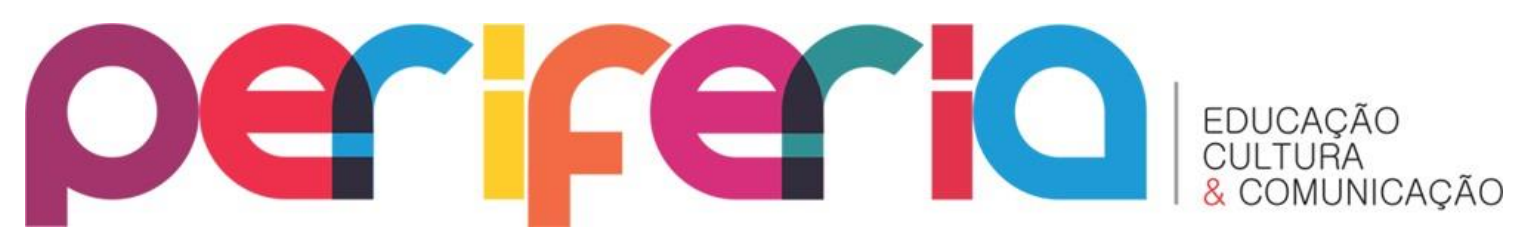

que foram detectados, ao longo da pesquisa, diferentes níveis de negociação, que foram associados a diferentes estratégias de jogar o jogo político escolar. Nesse sentido, algumas ações caracterizaram-se por uma tentativa mais forte de negociação e concessão, como no caso da Festa Junina e da Semana Política, outras pelas brechas, como no caso do SISV. Outras ainda remetiam à subordinação, como a organização das eleições do grêmio, de campeonatos esportivos, peças teatrais e festas comemorativas, como Dia dos Pais, Dias das Mães, festa de fim de ano etc. Cada um desses eventos, incluindo outras ações do grêmio, como a organização de grupos de debate no Facebook em uma página intitulada Assembleia Geral, em que os estudantes eram convidados a deixar suas opiniões sobre seu próprio cotidiano escolar, foi compreendido como espaço de experiência política formativa, pois possuía a capacidade de mobilização e negociação de espaços de atuação na escola.

Esse entendimento justificou-se pelas diferentes posturas assumidas pelos estudantes e pela coordenação diante de diversas situações envolvendo a negociação de espaços de ação do grêmio no interior do colégio. A manifestação do político nesses diversos espaços chama a atenção para outras formas de ação e atuação política expressas no cotidiano escolar, revelando ser necessário abranger o olhar dos pesquisadores sobre os meandros da política manifestos nas situações do dia a dia da escola. Escolher caminhos de ação, dependendo dos fins almejados, negociar posições e estabelecer agendas, reivindicações e compromissos são atitudes políticas em sua essência, no sentido de que contribuem nas experiências políticas formativas dos indivíduos. Quando um grupo de alunos resolve questionar sua realidade e transformá-la, adotando estratégias de convivência na relação com determinada personificação de amigo-inimigo, como não acreditar que existe implícita nessas ações e vivências uma experiência política formativa? E, se ela existe, como não legitimá-la?

\section{CONSIDERAÇÕES FINAIS}




\section{0 -}

- Eu acho que esse nosso mandato foi muito bom. Porque a gente conseguiu fazer coisas que nunca tínhamos feito antes. Foi bem questionável, no sentido de que a gente questionou bastante a forma da escola [fala de um dos integrantes do Spoleta 2.0].

A declaração do estudante revela que, em sua opinião, o mandato do Spoleta 2.0 foi positivo, no sentido de que questionou a forma da escola. Esse questionamento foi fruto de uma posição assumida pelo grêmio de transformar sua realidade escolar, via construção de caminhos participativos e brechas de atuação, buscando atenuar a sensação de controle dada sua posição de submissão na hierarquia e burocracia escolar à C. P. Na pesquisa, as diferentes estratégias, negociações e os espaços de atuação foram compreendidos como construção de vias políticas participativas no interior da escola. Dessa maneira, a configuração do jogo político escolar pode ser entendida como a busca/realização/experiência/vivência formativa que, com base em uma visão ampliada de política, possibilita o reconhecimento da manifestação do político no cotidiano escolar como relacionada à produção da convivência entre grupos nele manifestos.

De acordo com o pensamento de Carl Schmitt (BOBBIO, 1986), a esfera da Política coincide com a da relação amigo-inimigo, no sentido de que serve aos conflitos humanos. Partindo desse ponto de vista, é possível afirmar que a observação de jogos políticos e relações de poder deve concentrar-se nas ações humanas, por moverem grupos distintos, postos ora em posição de conflito, ora de aliança. A base do jogo político, desse modo, leva em consideração dois lados disputando uma posição, um espaço de atuação e formas de ação.

A bandeira de uma transformação interna, no sentido de modificar determinados aspectos da cultura escolar, foi compreendida como ação política. Nesse sentido, a partir da construção de espaços de resistência, de confrontação e de concessão, os integrantes do Spoleta 2.0 construíram uma gestão marcadamente política, assentada num jogo político que utilizou a via de negociação como sua regra básica. Foi possível perceber, com a investigação, que o cerne da atividade política desses estudantes era a luta pela abertura de caminhos participativos em sua escola, 


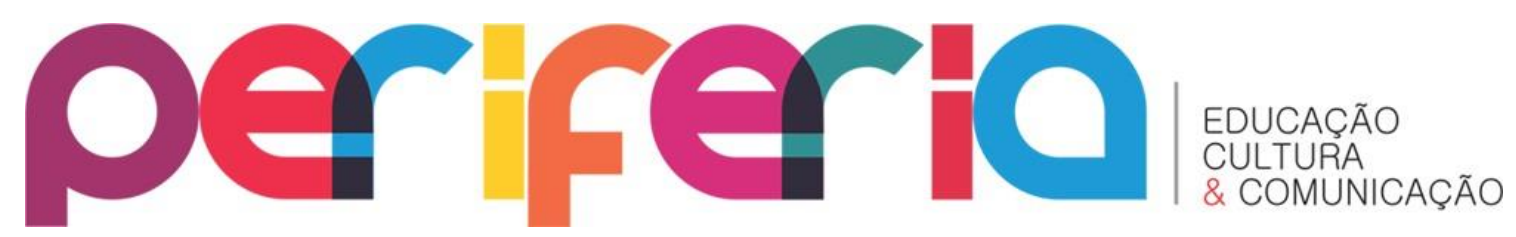

uma ação transformadora que buscou, com base em estratégias de convivência, mudar o cotidiano escolar dos jovens.

Na visão de Colliot-Thélène (1999), há uma perda dos parâmetros de compreensão e vivência política tal como eram vistas no final da Segunda Guerra Mundial, quando as disputas ideológicas que marcavam oposições entre a esquerda e a direita estruturavam o campo político. Essa concepção foi responsável, de certa forma, pela redução do significado de política à luta de forças pelo poder, cujas instituições políticas (sejam partidos de situação, oposição ou o próprio Estado) seriam consideradas as referências centrais à atividade política. A autora chama a atenção, entretanto, para o fato de que ao longo dos anos essa concepção, considerada por ela como uma posição estrita acerca da política, sofreu modificações.

Essas mudanças estariam relacionadas à perda de confiança e desmoralização da atividade política institucional, incluindo sobretudo a ineficiência do Estado como provedor de serviços básicos e a corrupção, crítica direcionada à atuação dos políticos profissionais. A principal consequência dessa "crise" é a disseminação de uma visão negativa sobre a política estrita, considerada problemática e distante dos indivíduos (cidadãos). Contudo, conforme argumenta a autora, é dessa situação adversa que seria possível a eclosão de uma nova concepção de política, ampliada aos espaços cotidianos, onde ela se tornaria plausível, palpável, próxima da intervenção das pessoas comuns. É como se necessitássemos de uma nova política, uma nova roupagem para compreendê-la, não como uma esfera social, um campo de poder e de forças, mas como prática construída no cotidiano, nas relações diárias entre grupos que convivem num mesmo território.

Em tempo: a concepção institucionalizada de política, que delega poderes a alguns que deveriam representar o coletivo, foi duramente criticada pelos estudantes. Visto como problemático, o conceito de política restrito às lutas pelo poder e às instituições político-partidárias apareceu na palavra dos jovens de forma 


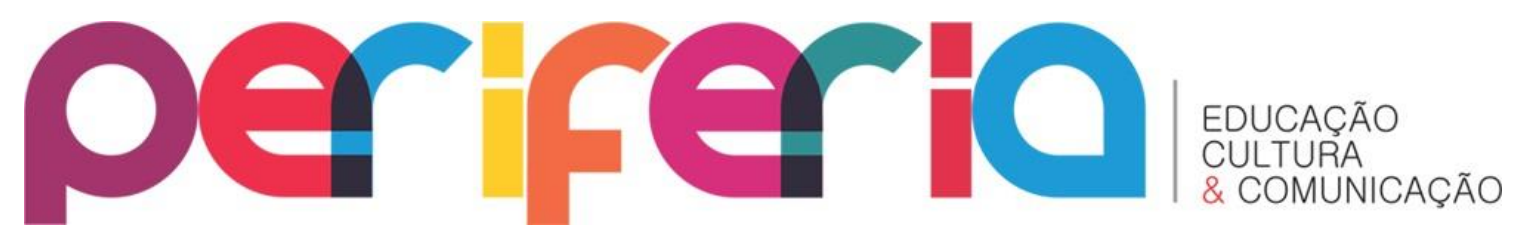

ressignificada.

- Assim, acho que a ação política não se limita à liderança. Mesmo que seja uma coisa só pra atingir os alunos daqui da escola, já é um movimento político do qual a gente se orgulha [trecho retirado do áudio da roda de conversa realizada na escola confessional].

A interface entre juventude e política aparece em diversas falas como relacionada ao poder local, às ações que de fato podem modificar e transformar a realidade envolvida, que não precisa ser o país, a nação, ou até mesmo o modo de produção, mas que pertencem aos problemas diários. Ela se materializa em experiências e vivências políticas como maneira de nos relacionarmos com o outro.

- Acho que eu vou pegar uma frase do Platão agora. Política não é tudo, sabe, mas tudo é política. Então, a política cabe aqui na entrevista, está quando eu vou pedir o auditório [a entrevista foi realizada no auditório após a assembleia sobre a organização da festa junina], quando eu vou, sei lá, fazer política num debate ou numa eleição. Então a política vai além do que dizem. A política é a conversa, é o diálogo, sabe, é informação, diplomacia. Pra construir uma sociedade você precisa disso (Francisco, do 3o ano, integrante do grêmio).

- Política é basicamente relações de poder e tentar agregar as pessoas para daí fazer de tudo pra conseguir fazer algo. Qualquer poder que seja.

-E é isso que o grêmio tem que fazer na escola? [fala da pesquisadora].

- Sim. Ele tem que agregar os alunos pra que eles tenham algum poder, pra que eles tenham voz e aí mudar as coisas (Felipe, 3으ono, integrante do grêmio).

Assim, o ideal de transformação, tão presente nos atos revolucionários da "geração de 68", que ousou olhar e questionar a sociedade como um todo, encontrava-se na atual geração construído sob outra forma. Os ideais, os sonhos e as utopias transformaram-se em uma espécie de consciência local, de transformações pontuais, pequenas, mas tidas como possíveis. Nesse ponto, reivindicar mudanças e transformações que possuem como alvo sua escola poderia ser compreendido como estando inseridas em práticas políticas atuais, relacionadas à abertura do campo político, que pode ter na escola espaço propício ao 


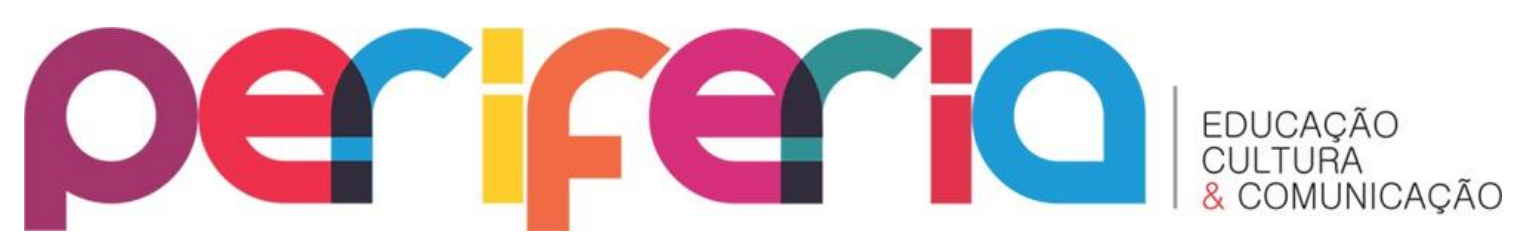

reconhecimento e à manifestação do político no cotidiano escolar ${ }^{8}$.

Essas expressões do político no cotidiano escolar devem ser reconhecidas como experiência política formativa, sendo tão importantes para o processo do ensino-aprendizagem quanto o currículo formal, pois estimulam processos interativos e de reflexão política, saberes centrais no mundo contemporâneo, em que parece que a política está se reinventando.

Todavia, esses saberes políticos, que envolvem uma espécie de natureza política humana, não devem prescindir de uma formação política crítica ao funcionamento da democracia representativa. Isso significa que uma visão ampliada da política como experiência formativa não renega a formação cidadã como elo fundamental da formação política dos jovens. Nesse sentido, se os estudantes não se sentem representados e acreditam que a política partidária não tem sentido, pois é distante dos homens comuns, cabe a nós, como sociedade, também nos perguntarmos o papel do ensino na transformação desse cenário, ao invés de apenas constatar essa realidade. Se a política pode assumir outros contornos, qual o lugar das instituições de ensino na construção das experiências políticas formativas desse "novo" cidadão? Continuam atuais, assim, as reflexões que insistem na importância da formação para a cidadania como criação de uma consciência política de mundo que envolva tanto aspectos formais da política como forma de governo quanto intersubjetivos, da política como fruto da convivência humana.

\section{REFERÊNCIAS}

BOBBIO, N. Dicionário de política. 2ª ed. Brasília: Ed. UnB, 1986.

CARRANO, Paulo. Jovens e participação política. In: SPOSITO, Marília (coord.). Juventude e escolarização (1980-1998). Brasília: MEC/Inep/Comped, 2002.

COLLIOT-THÈLÉNE, C. O conceito de política posto à prova pela mundialização. Revista de Sociologia e Política, n. 12, p. 7-20, jun. 1999.

8 Boaventura de Sousa Santos (1997), refletindo sobre o social e o político na pós-modernidade, propõe a formulação de uma nova teoria de democracia (em vista de uma nova teoria da emancipação), em contraponto ao conceito de democracia liberal. Dentro da nova teoria, o campo político se prolongaria a todos os espaços estruturais da interação social. Essa perspectiva possibilita o alargamento também da compreensão sobre o que seja participação política, que, fragmentada em ações pontuais, pode emergir em/sob diferentes espaços de sociabilidade. 


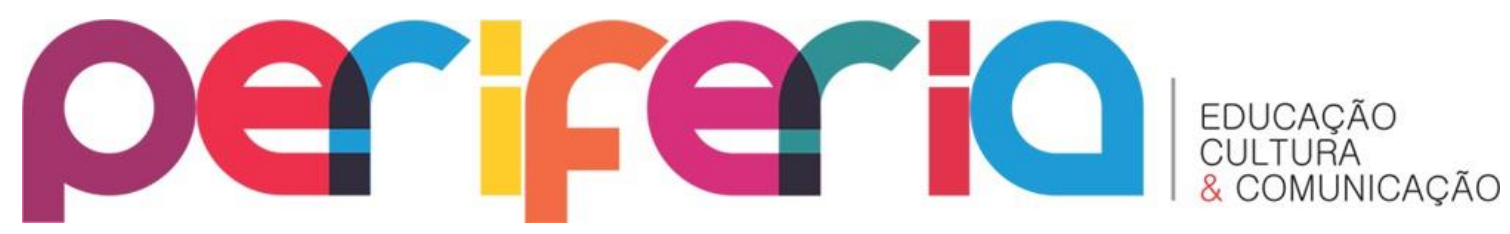

DAYRELL, J. A escola como espaço sócio-cultural. In: DAYRELL, Juarez (org.). Múltiplos olhares sobre educação e cultura. Belo Horizonte: Ed. UFMG, 1999.

FILHO, L. M. de F. F.; VIDAL, D.; PAULILO, A. et.al. A cultura escolar como categoria de análise e como campo de investigação na história da educação brasileira. Educação e Pesquisa, São Paulo, v. 30 no 1, p. 139-159, jan./abr. 2004.

FORACCHI, Marialice. $O$ estudante e a transformação da sociedade brasileira. São Paulo: Companhia Editora Nacional, 1965.

MESQUITA, M. R. Movimento estudantil brasileiro: práticas militantes na ótica dos novos movimentos sociais. Revista Crítica de Ciências Sociais, no 66, p. 117-149, out. 2003.

MISCHE, Ann. De estudantes a cidadãos: redes de jovens e participação política. Revista Brasileira de Educação [on line], no 5, p.134-150, maio/jun./jul./ago. 1997.

PARO, V. A educação, a política e administração: reflexões sobre a prática do diretor da escola. Educação e Pesquisa, São Paulo, v. 36, no 3, p. 763-778, set./dez. 2010.

Estrutura da escola e prática educacional democrática. 2007. Disponível em:

www.anped.org.br/reunioes/30ra/trabalhos/GT-2780--Int.pd. Acesso em: jan.2012.

- Implicações do caráter político da educação para a administração da escola

pública. Educação e Pesquisa, São Paulo, v. 28, p. 11-23, jul./dez. 2002.

Educação para a democracia: o elemento que faltava na discussão da

qualidade do ensino. Revista Portuguesa de Educação, Universidade do Minho, v. 13, no 1, p.23-38, 2000.

PINTO, Camila Moura. Grêmios escolares e novos caminhos participativos: um estudo de caso. Dissertação (Mestrado em Educação). Departamento de Educação, Pontifícia Universidade Católica do Rio de Janeiro. Rio de Janeiro, 2013.

SANTOS, B. S. Pela mão de Alice: o social e o político na pós-modernidade. 13a ed. São Paulo: Cortez, 2010.

SCHMITT, C. O conceito do politico. Petrópolis: Vozes, 1992.

SPOSITO, Marília (et al.). Estado da arte sobre juventude na pós-graduação brasileira: educação, ciências sociais e serviço social (1999-2006). V. 1 e 2. Belo Horizonte: Argvmentvm, 2009.

. (coord.). Juventude e escolarização (1980-1996). Brasília: MEC/Inep/Comped, 2002.

Algumas hipóteses sobre as relações entre movimentos sociais, juventude e educação. Revista Brasileira de Educação [on line], no 13, p.73-94, jan./fev./mar./abr. 2000.

YIN, R. Estudo de caso: planejamento e métodos. 4a ed. Porto Alegre: Bookman, 2010. ZIBAS, D. M. L.; FERRETTI, C.; TARTUCE, G.. Micropolítica escolar e estratégias para o desenvolvimento do protagonismo juvenil. Cadernos de Pesquisa, v. 36, № 127, p. 5185, jan./abr. 2006. 